\title{
Impact resistance of deflection-hardening fiber reinforced concretes with different mixture parameters
}

\author{
Qais S. Banyhussan ${ }^{1}$ | Gürkan Yıldırım ${ }^{2}$ | Özgür Anıl ${ }^{3}$ (6) | Recep T. Erdem ${ }^{4}$ | Ashraf Ashour ${ }^{5}$ | \\ Mustafa Şahmaran ${ }^{6}$
}

${ }^{1}$ Department of Highway and Transportation Engineering, Al-Mustansiriya University,

Baghdad, Iraq

${ }^{2}$ Department of Civil Engineering, Kırıkkale

University, Kırıkkale, Turkey

${ }^{3}$ Department of Civil Engineering, Gazi

University, Ankara, Turkey

${ }^{4}$ Department of Civil Engineering, Manisa Celal

Bayar University, Manisa, Turkey

${ }^{5}$ Department of Civil Engineering, University of Bradford, Bradford, UK

${ }^{6}$ Department of Civil Engineering, Hacettepe

University, Ankara, Turkey

Correspondence

Gürkan Yıldırım, Department of Civil

Engineering, Kırıkkale University, Kırıkkale,

Turkey.

Email: gyildirim@kku.edu.tr;

gurkanyildirimgy@gmail.com
The impact behavior of deflection-hardening High Performance Fiber Reinforced Cementitious Concretes (HPFRCs) was evaluated herein. During the preparation of HPFRCs, fiber type and amount, fly ash to Portland cement ratio and aggregate to binder ratio were taken into consideration. HPFRC beams were tested for impact resistance using free-fall drop-weight test. Acceleration, displacement, and impact load versus time graphs were constructed and their relationship to the proposed mixture parameters were evaluated. The paper also aims to present and verify a nonlinear finite element analysis, employing the incremental nonlinear dynamic analysis, concrete damage plasticity model, and contact surface between the dropped hammer and test specimen available in ABAQUS. The proposed modeling provides extensive and accurate data on structural behavior, including acceleration, displacement profiles, and residual displacement results. Experimental results which are further confirmed by numerical studies show that impact resistance of HPFRC mixtures can be significantly improved by a proper mixture proportioning. In the presence of high amounts of coarse aggregates, fly ash, and increased volume of hybrid fibers, impact resistance of fiberless reference specimens can be modified in a way to exhibit relatively smaller displacement results after impact loading without risking the basic mechanical properties and deflection-hardening response with multiple cracking.

\section{KEYWORDS}

ABAQUS, coarse aggregate, deflection-hardening, fly ash, high performance fiber reinforced concrete (HPFRC), impact

\section{1 | INTRODUCTION}

Conventional concrete is the most widely used construction material in the world although it is relatively brittle. To account for the high brittleness of conventional concrete materials, High Performance Fiber Reinforced Concretes (HPFRCs) have been manufactured in the last few decades. HPFRCs are characterized by their dominant performance in

Discussion on this paper must be submitted within two months of the print publication. The discussion will then be published in print, along with the authors' closure, if any, approximately nine months after the print publication. accounting for tensile forces/strain and crack occurrence/propagation. According to previous studies, the increased crack bearing ability of HPFRCs due to strain and/or deflectionhardening behavior offsets many common durability concerns. ${ }^{1-4}$ Given the materials' enhanced performance, many studies have focused on their basic mechanical and durability properties. ${ }^{5-7}$ Due to the crack bearing ability and controlled cracking behavior of HPFRCs, their self-healing behavior has also been studied extensively. ${ }^{8-10}$ However, studies into more complex material properties such as resistance to impact loading are lacking in the current literature. 
Thus, studying the impact resistance of HPFRC mixtures, especially those characterized by deflection-hardening behavior is believed to make a valuable contribution to the current literature.

When under the influence of impact loads, conventional concrete materials fail in tensile mode with a softening response after reaching to peak point, given their quasibrittle nature. ${ }^{11-22}$ There is no established standards or methods for impact testing in recent studies. ${ }^{23-26}$ However, American Society for Testing and Materials E23 regulations improved the test setup performance significantly and gave good starting point for the limits of impact experiments. ${ }^{27}$ Experimental impact studies in literature are generally categorized into two main segments. One of them depends on the investigation of specimens under impact loads that are applied by test equipments. These types of studies are concentrated mostly on steel materials. Other studies use equipment with mechanisms that drop masses from height. This method is mostly used for the impact testing of concrete. ${ }^{28,29}$ Similarly, here, an impact test setup that was designed by the authors and drops a constant weight from a height was used for testing of HPFRC specimens.

According to Maalej et al. ${ }^{30}$, there is a clearer relationship between impact resistance and tensile strength than that between impact resistance and compressive strength of concrete. It was also concluded that structural elements manufactured with Engineered Cementitious Composites (ECC) (a relatively appealing branch of HPFRCs) characterized by strain-hardening response and multiple microcracking behavior under tensile/shear loads can enhance impact behavior considerably. ${ }^{30}$ It may be thus stated that impact resistance can be improved by delaying the crack formation through strain/deflection-hardening response accompanied by multiple microcracking and enhancing the strength in tension.

In many types of HPFRC mixtures, including ECC, the amount and maximum size of coarse aggregates are restricted to achieve strain/deflection-hardening response. One reason for that is the nonuniform distribution of individual fibers in the presence of high amounts of coarse aggregates. When aggregates with larger than the average particle sizes are used, spacing of individual fibers causes inadequate dispersion/balling, with the balling effect being more pronounced with increased maximum aggregate size. ${ }^{31}$ Generally, an increase in the size of aggregate particles causes more clumping and greater interaction of the fibers. ${ }^{32}$ Another reason for not using coarse aggregates is associated with the increased matrix fracture toughness values in the presence of coarse aggregates which increases the fracture toughness of the brittle matrix and significantly lowers the ductility of ultimate material. ${ }^{33}$ The influence of both of these factors is likely to exacerbate when mixtures are reinforced with more than one type of fiber with varying properties. Thus, HPFRCs are generally manufactured with relatively small-size aggregates, regardless of the selected fiber system (single or hybrid). ${ }^{34,35}$ While preparing HPFRC mixtures, the use of small aggregates is beneficial in uniform distribution of fibers, although this also increases the Portland cement (PC) amount as the main binder which is not cost-effective and more detrimental to dimensional stability than systems incorporating coarse aggregates. To reduce the chance of dimensional instability and overall cost of HPFRC systems, cement is commonly replaced with industrial byproducts (e.g., fly ash [FA], slag etc.). Lower toughness values can be acquired with the use of such by-products which may favor the materials' ductility even in the presence of coarse aggregates. ${ }^{32}$

Few studies have targeted the development of HPFRC mixtures with strain/deflection-hardening capability incorporating coarse aggregates. ${ }^{36,37}$ In a recent study by the authors, deflection-hardening HPFRC mixtures with single and hybrid fibers were developed using different amounts of FA and coarse aggregates with a maximum size of $12 \mathrm{~mm}^{7}$ Although the basic mechanical properties (compressive strength, flexural strength, and mid-span beam displacement) of HPFRC mixtures manufactured in the cited study were notable, studies detailing the impact performance of such materials are limited. ${ }^{16,38-41}$ Moreover, to the authors' best knowledge, there are no studies available in the literature dealing with the impact performance of deflection-hardening HPFRC mixtures in the presence of large amounts of coarse aggregates. To fill that knowledge gap, a follow-up study to that of Banyhussan et al. ${ }^{7}$ was undertaken, focusing mainly on the impact resistance of previously developed HPFRC mixtures with deflection-hardening capability. Beam specimens of different HPFRC mixtures were produced and tested for their impact resistance after free-fall drop-weight tests. HPFRCs were produced by taking the type and amount of fibers, FA to $\mathrm{PC}$ ratio $(\mathrm{FA} / \mathrm{PC})$ and aggregate to binder ratio (A/B) into account. To observe the possible effects of these parameters on the impact performance, 24 beams were tested. Tested beam specimens were modeled in a finite element program (ABAQUS), incremental nonlinear dynamic analysis was performed, and the effectiveness of the developed finite element model in reflecting the impact behavior of HPFRC beam specimens was investigated.

\section{2 | EXPERIMENTAL PROGRAM}

To characterize the impact behavior of HPFRCs, $50 \times 50 \times 750 \mathrm{~mm}^{3}$ beam specimens were produced without any steel rebars. Table 1 shows the experimental variables taken into consideration. While preparing the mixtures, the type/amount of fibers, $\mathrm{FA} / \mathrm{PC}$, and $\mathrm{A} / \mathrm{B}$ ratios were selected as variant parameters. Three fiber types, FA/PC ratio, and $\mathrm{A} / \mathrm{B}$ ratio were chosen. Beam specimens produced with 24 different mixtures were then tested for their impact 
TABLE 1 Ingredients used for the production of mixtures (units are in $\mathrm{kg} / \mathrm{m}^{3}$ ) and basic mechanical property results after 28 days

\begin{tabular}{|c|c|c|c|c|c|c|c|c|c|c|c|c|c|c|}
\hline \multicolumn{2}{|c|}{ Mixture } & \multirow[b]{2}{*}{ PC } & \multirow[b]{2}{*}{ FA } & \multirow[b]{2}{*}{ SF } & \multicolumn{2}{|c|}{ Aggregates } & \multirow[b]{2}{*}{ Water } & \multirow[b]{2}{*}{ HRWRA } & \multicolumn{3}{|c|}{ Fibers } & \multicolumn{3}{|c|}{ Mechanical properties } \\
\hline$\#$ & ID & & & & Fine & $\overline{\text { Coarse }}$ & & & $\overline{\mathbf{P}}$ & $\mathbf{S}$ & $\mathbf{N}$ & Comp. St. (MPa) & Flex. St. (MPa) & Flex. Dis. (mm) \\
\hline 1 & P0S0N0_0.20_1.0 & 690 & 138 & 48 & 495 & 380 & 351 & - & - & - & - & 50.6 & 3.20 & 0.22 \\
\hline 3 & P0S0N0_0.70_1.0 & 481 & 337 & 34 & 483 & 372 & 341 & - & - & - & - & 31.3 & 3.00 & 0.20 \\
\hline 4 & P0S1N0_0.20_1.0 & 683 & 137 & 48 & 490 & 376 & 347 & 0.6 & - & 78 & - & 47.9 & 6.00 & 1.60 \\
\hline 5 & P0S1N0_0.45_1.0 & 562 & 253 & 39 & 482 & 370 & 342 & 0.5 & - & 78 & - & 48.5 & 5.48 & 1.49 \\
\hline 7 & P1S1N0_0.20_1.0 & 675 & 135 & 47 & 486 & 374 & 343 & 0.9 & 13 & 78 & - & 52.9 & 5.88 & 1.93 \\
\hline 8 & P1S1N0_0.45_1.0 & 555 & 250 & 39 & 479 & 368 & 337 & 0.8 & 13 & 78 & - & 44.6 & 7.95 & 1.75 \\
\hline 9 & P1S1N0_0.70_1.0 & 472 & 330 & 33 & 472 & 363 & 334 & 0.5 & 13 & 78 & - & 38.1 & 7.58 & 1.58 \\
\hline 10 & P1S1N0_0.20_1.5 & 579 & 116 & 41 & 622 & 478 & 294 & 1.8 & 13 & 78 & - & 55.0 & 8.83 & 1.13 \\
\hline 11 & P1S1N0_0.45_1.5 & 477 & 215 & 33 & 614 & 472 & 290 & 1.5 & 13 & 78 & - & 44.6 & 8.03 & 1.38 \\
\hline 15 & P1S1N0_0.70_2.0 & 356 & 249 & 25 & 711 & 547 & 252 & 1.6 & 13 & 78 & - & 43.6 & 7.48 & 1.23 \\
\hline 16 & P0.5S1N0.5_0.20_1.0 & 675 & 135 & 47 & 486 & 374 & 343 & 1.0 & 6.5 & 78 & 5.7 & 51.9 & 6.27 & 1.47 \\
\hline 17 & P0.5S1N0.5_0.45_1.0 & 555 & 250 & 39 & 479 & 368 & 337 & 0.8 & 6.5 & 78 & 5.7 & 45.4 & 7.20 & 1.70 \\
\hline 18 & P0.5S1N0.5_0.70_1.0 & 472 & 330 & 33 & 472 & 363 & 334 & 0.7 & 6.5 & 78 & 5.7 & 40.9 & 6.60 & 1.77 \\
\hline 19 & P0.5S1N0.5_0.20_1.5 & 578 & 116 & 40 & 623 & 479 & 294 & 3.5 & 6.5 & 78 & 5.7 & 60.2 & 6.98 & 1.30 \\
\hline 20 & P0.5S1N0.5_0.45_1.5 & 477 & 215 & 33 & 614 & 472 & 290 & 3.3 & 6.5 & 78 & 5.7 & 54.5 & 8.45 & 1.78 \\
\hline 21 & P0.5S1N0.5_0.70_1.5 & 405 & 284 & 28 & 610 & 469 & 287 & 3.0 & 6.5 & 78 & 5.7 & 46.9 & 7.03 & 1.83 \\
\hline 22 & P0.5S1N0.5_0.20_2.0 & 505 & 101 & 35 & 726 & 559 & 257 & 5.0 & 6.5 & 78 & 5.7 & 60.4 & 8.30 & 1.43 \\
\hline 23 & P0.5S1N0.5_0.45_2.0 & 417 & 188 & 29 & 718 & 552 & 254 & 4.9 & 6.5 & 78 & 5.7 & 56.3 & 7.13 & 1.27 \\
\hline
\end{tabular}

resistance using free-fall drop-weight testing with a specific impact loading.

\section{1 | Materials and mixture proportions}

CEM I 42.5R ordinary PC, FA with lime content of $9.8 \%$ and silica fume (SF) were used for the production of HPFRC mixtures. The total SF amount used was constant at $7 \%$ of PC weight. Surface areas of PC, FA, and SF were 325, 290, and $19,080 \mathrm{~m}^{2} / \mathrm{kg}$, respectively. Particle size distributions of the raw materials can be found in Ref. 7 .

Mixtures were produced with three FA/PC ratios $(0.20$, 0.45 , and 0.70 ) and fine and coarse aggregates. Fine aggregate was river sand with fineness modulus of 2.67 and coarse aggregate was crushed limestone with maximum aggregate size of $12 \mathrm{~mm}$. To find the well-graded aggregate combination, 0.45 power chart method using the Fuller formula was adopted and a gradation curve closest to the maximum density curve was obtained. Combined aggregate gradation was achieved using $57 \%$ fine and $43 \%$ coarse aggregates, by weight. Mixtures' total aggregate (coarse + fine) to binder $(\mathrm{PC}+\mathrm{FA}+\mathrm{SF})$ ratios $(\mathrm{A} / \mathrm{B})$ were $1.0,1.5$, and 2.0. Polycarboxylate-ether-based high range water reducing admixture (HRWRA) was also used to achieve desired workability. Mixtures produced with different $\mathrm{FA} / \mathrm{PC}$ and $\mathrm{A} / \mathrm{B}$ ratios and amounts/types of fibers required different HRWRA amounts to obtain uniform fiber distribution and nearly self-compacting properties. Fresh properties of HPFRC mixtures were measured using slump test. After slump tests, average slump flow measurements were made. Depending on the mixture type, slump flows ranged between 660 and $700 \mathrm{~mm}$. Polyvinyl-alcohol (P), hooked-end steel $(\mathrm{S})$, nylon $(\mathrm{N})$ fibers were used. $\mathrm{P}$ fibers were with length of $18 \mathrm{~mm}$, diameter of $0.20 \mathrm{~mm}$, tensile strength of 1,000 MPa, elastic modulus of $29 \mathrm{GPa}$, and specific gravity of 1.30. S fibers were with length of $30 \mathrm{~mm}$, diameter of $0.75 \mathrm{~mm}$, tensile strength of $1,100 \mathrm{MPa}$, elastic modulus of $200 \mathrm{GPa}$, and specific gravity of 7.30. N fibers were with length of $19 \mathrm{~mm}$, diameter of $0.05 \mathrm{~mm}$, tensile strength of $966 \mathrm{MPa}$, elastic modulus of $25 \mathrm{GPa}$, and specific gravity of 1.14. A moderate fiber volume $(\leq 2 \%)$ was used in all HPFRC mixtures.

Twenty four HPFRC mixtures were produced with constant water to binder ratio (W/B) of 0.40 . Ingredients used for the production of all mixtures are tabulated in Table 1 showing that several letters and numbers were used for denomination. For example, in the 16th mixture (P0.5S1N0.5_0.20_1.0), P, S, and $\mathrm{N}$ fibers were used by $0.5,1.0$, and $0.5 \%$ of total mixture volume, respectively and 0.20 and 1.0 stand for $\mathrm{FA} / \mathrm{PC}$ and $\mathrm{A} / \mathrm{B}$ ratios, respectively.

Selection of different FA/PC and A/B ratios and fiber types/amounts were made based on the experience of 
authors from a recent study. ${ }^{7}$ In the cited study, preliminary tests on variety of HPFRC mixtures were performed using different $\mathrm{FA} / \mathrm{PC}$ and $\mathrm{A} / \mathrm{B}$ ratios together with fiber types/amounts. The selected proportions and ingredients were then decided depending on the achievement of optimal mechanical properties and deflection-hardening response coupled with multiple microcracking in the presence of as much coarse aggregates as possible.

\subsection{Mixing, sample preparation and testing}

A 40-1-capacity pan-type concrete mixer was used to manufacture mixtures, following the same procedures. The mixing steps of HPFRC mixtures were discussed in detail in Ref. 7. Beam specimens measuring $50 \times 50 \times 750 \mathrm{~mm}^{3}$ were produced for testing of flexural impact resistance under free-fall drop-weight testing. In addition to the impact tests, mechanical properties (compressive strength, flexural strength, and displacement) of different HPFRC mixtures were tested. Details of specimen dimensions and testing procedures related to basic mechanical properties of mixtures can be found in Ref. 7. Different from the specimens of mechanical property characterization in cited study, here, dogbone-shaped specimens were produced as well for uniaxial tensile tests, and the results obtained from these tests were used as raw data in numerical analysis along with the compressive strength test results. Considering the use of coarse aggregates in HPFRC mixtures, the geometry of dogbone-shaped specimens were selected in accordance with Ref. 42. Uniaxial tensile testing was conducted at a loading rate of $0.1 \mathrm{~mm} / \mathrm{min}$, and load and elongation results were recorded. Elongation was measured using two linear variable displacement transducers (LVDTs) attached to both sides of the central portion of dogboneshaped specimens. Uniaxial tensile measurements were taken from $30 \times 30 \mathrm{~mm}^{2}$ cross-sectional dimensions of dogbone specimens. ${ }^{42}$ All tests performed in this study were implemented after 28 days and details of the curing procedures were the same for all proposed specimens and explained in Ref. 7.

\section{3 | Test setup and instrumentation}

Impact loads were applied via test setup, details of which are provided in Figure 1. The test setup itself allows weights of varying magnitudes to be dropped from a maximum height of 2,500 $\mathrm{mm}$ onto specimens of varying dimensions. The weight and drop height of the hammer were kept constant during the experiment; a $9 \mathrm{~kg}$ hammer was dropped from a height of $600 \mathrm{~mm}$ to create impact loading from the same contact point for different beam specimens. High-strength $50 \times 50 \times 4 \mathrm{~mm}^{3}$ steel plates were placed on the contact points to prevent local fractures from the contact point and achieve distributed loading. Steel plates on which loading were applied were fixed to specimens with a mechanical anchor. A piece of rubber was placed between the plates and specimens to prevent stress localization due to surface roughness.

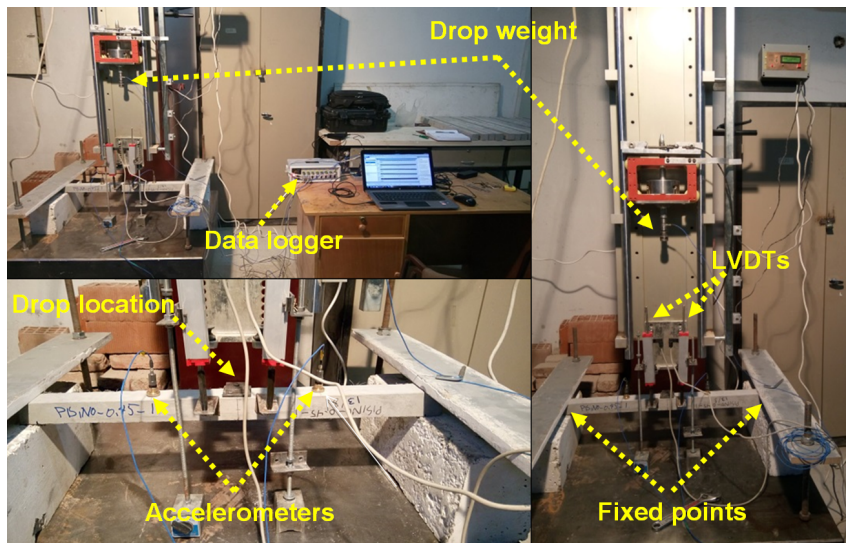

FIGURE 1 Free fall drop-weight test setup and view of beam specimen

Hammer weight, drop height, and impact energy level were selected accordingly to best trace the damage occurrence. The capacity of dynamic accelerometers and load cell were also considered during hammer weight and drop height selection. Special attention was paid in selection these two parameters to avoid very high energy impact, which can lead to exceedance of sensor limits and sudden, substantial damage introduction to specimens. To avoid these problems, levels of impact loads were limited to $52.97 \mathrm{~J}(600 \mathrm{~mm} \times$ $9.81 \mathrm{~m} / \mathrm{s}^{2} \times 9.0 \mathrm{~kg}$ [height of drop weight $\times$ gravitational acceleration $\times$ mass of drop weight]). Accelerations at two symmetrical points were measured to observe the effects of impact loading. Accelerometers were placed symmetrically $150 \mathrm{~mm}$ away from the point of impact loading and fixed with brass connections using mechanical anchors. Displacements were measured using two LVDTs placed symmetrically $50 \mathrm{~mm}$ away from the point of impact.

Figure 2 shows the view and layout of beam specimen ready for impact resistance testing. A dynamic data collection system with specifically designed software was used to properly save impact testing data. The loading created by the drop hammer was measured using a dynamic load cell. Impact velocity of the drop hammer was calculated by a speedometer placed on top of the hammer, and average of measured impact velocities of beam specimens was $3.5 \mathrm{~m} / \mathrm{s}$. These values, measured from different specimens, were very close to each other. Identical impact loading was applied to all specimens. The accelerometers and LVDTs were connected to the data logger with computerized software to record acceleration-time, displacement-time, and impact load-time graphs after applying the impact load.

\section{3 | RESULTS AND DISCUSSION}

\section{1 | Basic mechanical properties}

In this section, compressive strength, flexural strength, and flexural displacement results of HPFRCs are evaluated. For each mechanical property, six specimens were tested and 
(a)

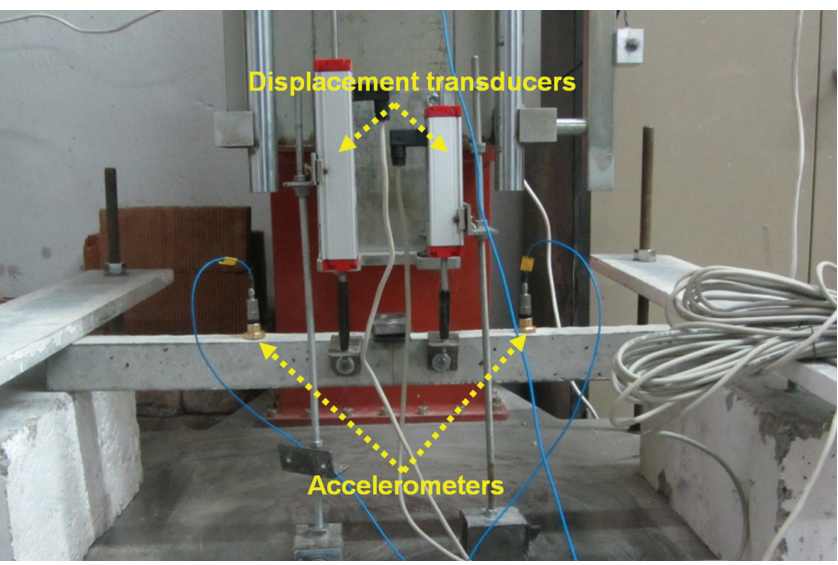

(b)

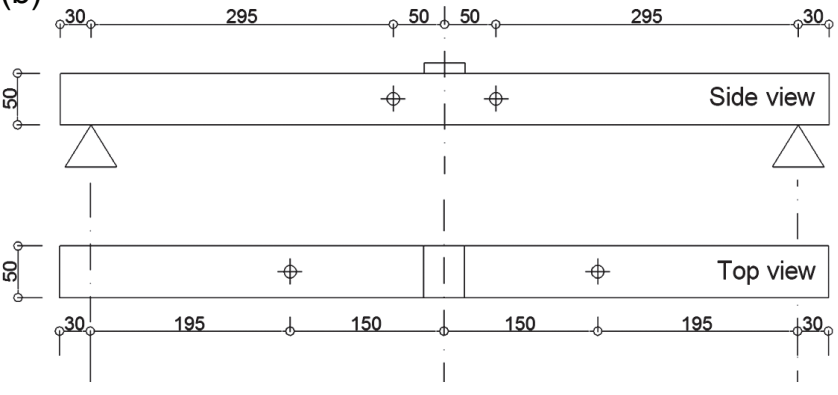

FIGURE 2 View of beam specimen ready for impact testing (a) and impact test layout (b) (all dimensions are in $\mathrm{mm}$ )

average results are presented in Table 1. Individual test results of specimens for each test were generally close to each other, with a coefficient of variation less than $5 \%$. Since the main topic of the present paper is to assess the impact behavior of newly-developed HPFRC mixtures, only a brief discussion of basic mechanical property results is presented below and further details on the related topic can be found in the companion paper. ${ }^{7}$

Increasing the amount of FA in mixtures having constant $\mathrm{A} / \mathrm{B}$ ratio and fiber types/amounts resulted in lower compressive strength. Observed behavior was associated with significantly lower cementing capability of FA retarding the attainment of higher strengths. Irrespective of the amount of FA used in the mixtures, utilization of different types of fibers led limited increments (approximately 10\%), indicating the slight contribution of fiber reinforcement on the compressive strength although the same is not true for flexural parameters (as will be detailed). Comparing the results of specimens with the same fiber combinations and FA/PC ratios, higher $\mathrm{A} / \mathrm{B}$ ratios increased the compressive strength results. This finding was attributed to the tortuosity of cracking path increasing the ultimate energy absorption capacity at final failure. ${ }^{7}$

For specimens with the same $\mathrm{A} / \mathrm{B}$ ratio, increasing the amount of FA generally reduced the flexural strength results. This was related with the factors reducing the compressive strength results. ${ }^{7,43}$ When similar $\mathrm{FA} / \mathrm{PC}$ ratios and fiber

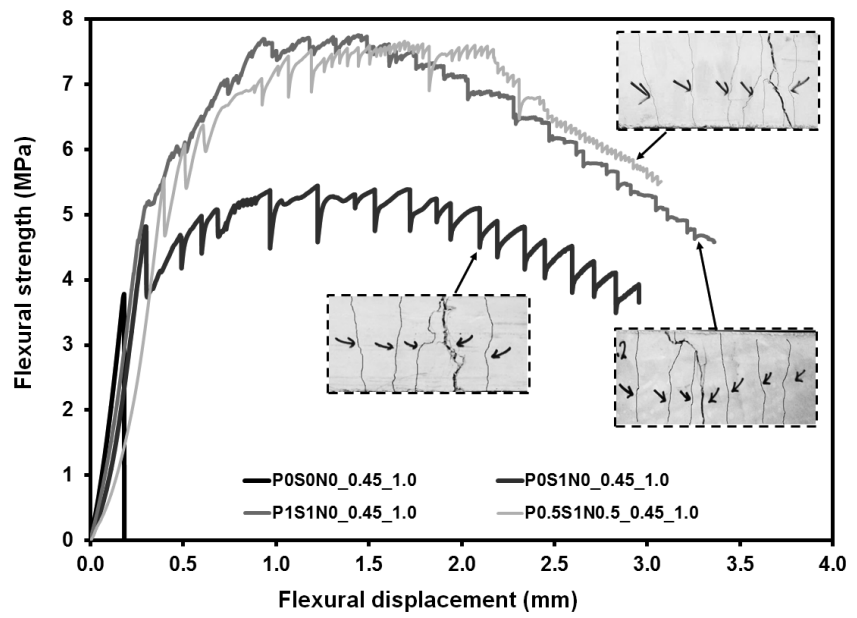

FIGURE 3 Effects of utilization of different types/dosages of fibers on typical flexural strength-displacement graphs and multiple microcracking behaviors of specimens

types/amounts were selected, increasing $\mathrm{A} / \mathrm{B}$ ratios evidently increased the flexural strength results. Similar to compressive strength results, this was attributed to the effect of higher coarse aggregate amounts increasing the tortuosity of cracking path until failure. Another explanation for this behavior could be the influence of significantly high amounts of FA utilization in HPFRC systems improving workability, fiber distribution, and staying intact for longer periods to be hydrated. Flexural strength results were considerably improved with the addition of fibers into HPFRCs (Table 1 and Figure 3). To exemplify, by addition of only $1 \%$ of $\mathrm{S}$ fibers (by volume) into reference mixtures with no fibers, $36 \%$ of improvement in average flexural strength results was achievable.

Average flexural displacement results varied based on different $\mathrm{FA} / \mathrm{PC}$ ratios although there was a general increasing trend in the values with increased FA amounts (Table 1). Beneficial effects of FA utilization on flexural displacement results were related with the capability of FA particles reducing the chemical bonding between synthetic fibers and matrix, fracture toughness, and increasing frictional bonding in interface. ${ }^{44}$ Another possible cause of this general trend can be the spherical morphology of FA particles favoring uniform fiber distribution. ${ }^{45}$ Increasing the A/B ratio of mixtures did not make any negative effect on flexural displacement suggesting that ductility can be modified with the use of proper amounts of FA even in the presence of high amounts of coarse aggregates. ${ }^{34}$ Fiber reinforcement was quite influential on flexural displacement results irrespective of FA/PC and A/B ratios. Although this was monitorable from Table 1, clearer comparisons can be made from Figure 3 which confirms significant improvements in both flexural strength and displacement results. Deflectionhardening response was also confirmed, since all mixtures with different types/amounts of fibers showed peak load and corresponding flexural displacement results greater than their 

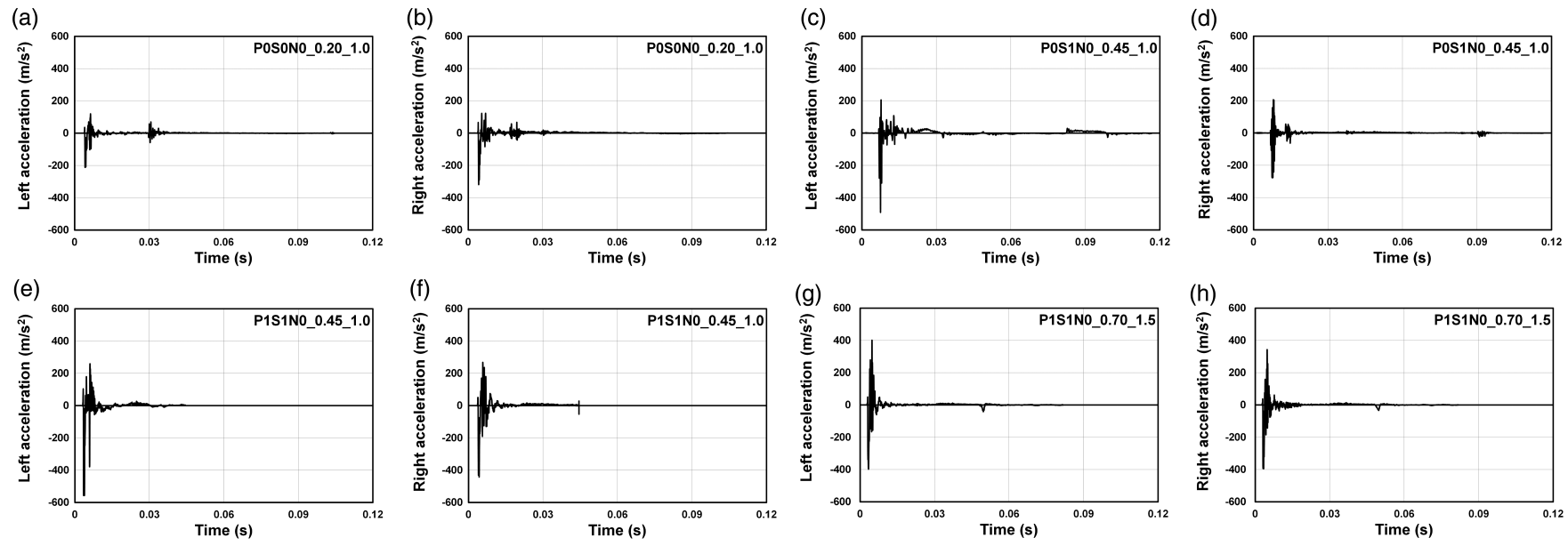

FIGURE 4 Representative acceleration versus time graphs for selected specimens from different mixtures

first cracking load and its corresponding flexural displacement recorded at the first cracking load. ${ }^{46}$ All specimens showed multiple microcracks, which is a direct consequence of deflection-hardening under bending (Figure 3).

\section{2 | Impact behavior}

Impact performances of HPFRCs were analyzed by evaluating data related to impact load versus time, acceleration versus time, and displacement versus time graphs. Representative acceleration, displacement, and impact load versus time graphs are shown in Figures 4,5, and 6, respectively. In Table 2, the maximum acceleration (for left/right points), displacement (for left/right points), and impact load results are summarized.

\subsection{1 | Effect of fibers}

Addition of fibers into HPFRC beams was very effective on impact performance and led to significant increments in acceleration results and decrements in displacement results depending on the type/amount of fibers. For specimens with an $\mathrm{A} / \mathrm{B}$ ratio of 1.0, the average of left and right acceleration results for specimens having only $\mathrm{S}$ fibers was $33 \%$ higher than that of reference specimens without fibers, while the average displacement results was $23 \%$ lower. For specimens having $\mathrm{S}$ and $\mathrm{P}$ fibers at the same $\mathrm{A} / \mathrm{B}$ ratio, the average of left and right acceleration results was $23 \%$ higher, and the average displacement was $23 \%$ lower compared to reference specimens. In mixtures with all three fiber types, the average of acceleration and displacement results were $29 \%$ higher and $42 \%$ lower than the reference specimens, respectively. These results clearly show that regardless of the type/amount, fibers improve the impact resistance of conventional concrete material for a given $\mathrm{FA} / \mathrm{PC}$ and $\mathrm{A} / \mathrm{B}$ ratio suggesting a more rigid behavior, higher residual impact capacity and endurance to impact loads. When impacted, frontal face of a beam specimen where the impact energy is introduced is subjected to the waves of compressive stress while the free distal (back) face is subjected to the waves of tensile stress (as the reflection of waves of compressive stress at the frontal face). It can thus be stated that specimens should be with adequate compressive strength in order not to crush and/or fail from the frontal face and should also be with adequate tensile strength to enhance the impact performance at the distal face. ${ }^{47}$ According to Table 1 , addition of $\mathrm{S}$ fibers did not make a marked contribution to compressive strength results of control specimens and failure took place because of the formation and localization of a single crack at the distal face of both reference and S-fiber-reinforced beams although this was much clearer for reference specimens (Figure 7). For the imposed impact energy, compressive strength of HPFRC beams were adequate to prevent crushing/failure from the frontal face although this was not the case for the flexural strength (especially for reference specimens). However, utilization of even $1 \%$ of $\mathrm{S}$ fibers in reference specimens did make a substantial contribution to impact performance by significantly favoring the flexural properties (Table 1 and Figure 7). All HPFRC mixtures (excluding reference mixtures numbered from 1 to 3 ) produced herein are characterized with deflection-hardening response through multiple microcracking (Figure 3 ). ${ }^{7}$ Significantly higher damage tolerance of HPFRC specimens with different type/amount of fibers than reference specimens allow them to absorb more flexural impact energy while better maintaining the overall integrity of specimens as seen from Figure 7.

Increased volume of fibers also enhanced the flexural impact resistance of HPFRC beams (Table 2, Figures 4 and 5). In the studies of Mao et al. ${ }^{48}$ and Barnett et al. ${ }^{49}$ where the blast resistance of Fiber-Reinforced Ultra-High Performance Concrete (FR-UHPC) slabs was studied, similar results were reported and concluded that increased postcracking tendency and deflection-hardening response (obtained from some of the specimens) lends FR-UHPFC specimens high flexural energy absorption capacity. According to Figure 2, increasing the fiber volume of HPFRC mixtures from 1 to $2 \%$, by volume led deflection-hardening 

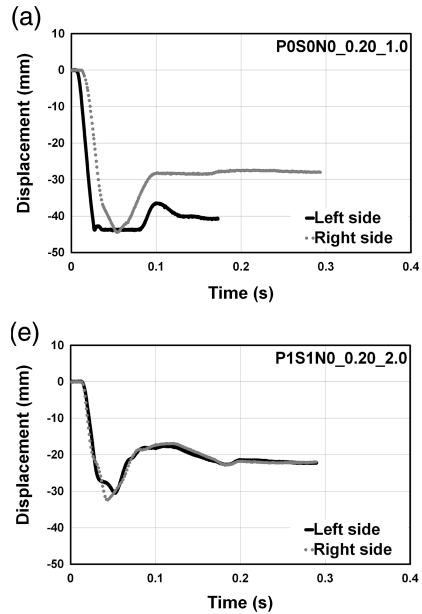

(b)
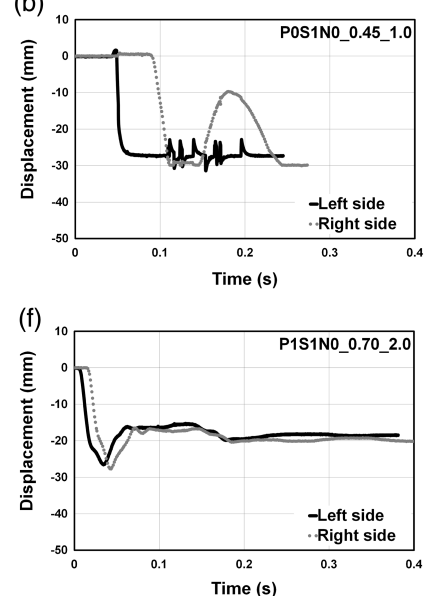

(c)
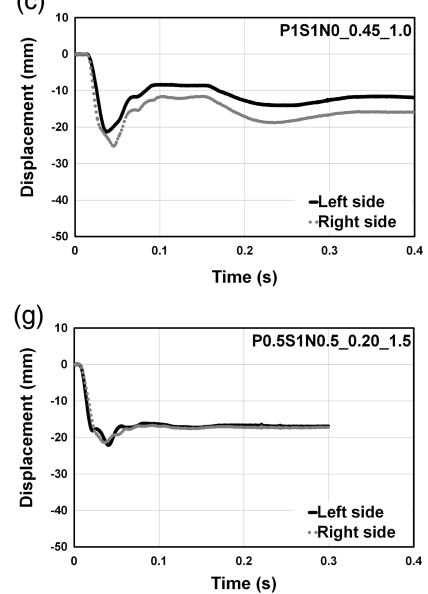
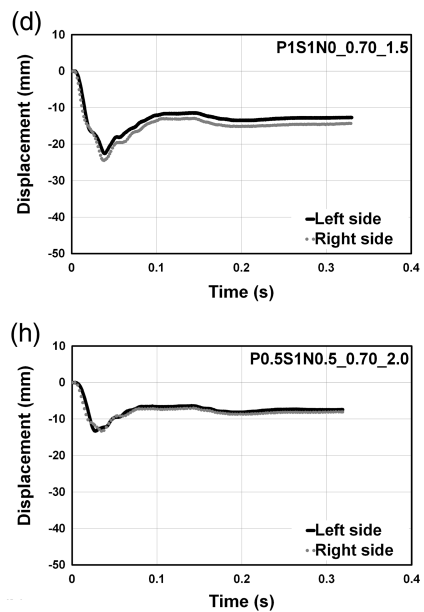

FIGURE 5 Representative displacement versus time graphs for selected specimens from different mixtures

response to be more pronounced (detailed discussions can be found in Ref. 7) and flexural toughness capacity (area under the plastic region of flexural stress-displacement plot) to be higher which can explain the enhanced impact resistance monitored at higher dosages of fiber reinforcement. Another reason for the observed improvements in the impact resistance of HPFRC mixtures at higher fiber dosages can be due to further improvements took place in the compressive strength results although they are limited (Table 1). It is likely that slightly increased compressive strength results at higher fiber dosages may lead to partial damping of impact load at the frontal face and reduction of the impact effect at the distal face. Moreover, at the same fiber dosage ( $2 \%$, by volume), $\mathrm{FA} / \mathrm{PC}$ ratio, and $\mathrm{A} / \mathrm{B}$ ratio, there were further improvements in flexural impact resistance of HPFRC specimens when fibers were hybridized (Figure 7). For example, average of left and right displacements of P0.5S1N0.5_0.20_1.0 mixture was $18.3 \mathrm{~mm}$ after impact loading while the same value was $26.8 \mathrm{~mm}$ for P1S1N0_0.20_1.0 mixture. A similar behavior was also noted for mixtures with different $\mathrm{FA} / \mathrm{PC}$ and $\mathrm{A} / \mathrm{B}$ ratios (Table 2). Although the compressive strength, flexural parameters, toughness of HPFRC specimens with two (S, P) or three $(\mathrm{S}, \mathrm{P}, \mathrm{N})$ different fibers were close (Table 1 and Figure 3), clear differences were noted in displacement and acceleration results of these specimens after the application of impact loading. This behavior could be related with the advantages of using $\mathrm{N}$ fibers instead of $\mathrm{P}$ fibers. Fracturing in concrete is a mechanism with multi-scale nature ${ }^{50}$ which means that it needs to be tackled by addressing cracking occurrences at different scales. Individual properties of $\mathrm{P}$ and $\mathrm{N}$ fibers are very close excluding their diameter which is $0.20 \mathrm{~mm}$ for $\mathrm{P}$ and $0.05 \mathrm{~mm}$ for $\mathrm{N}$ fibers. Therefore, it might have been possible for $\mathrm{N}$ fibers to bridge smaller microcracks than $\mathrm{P}$ fibers and contribute more to the flexural impact resistance of HPFRC mixtures by improving the materials' behavior before and/or right after the cracking formation. Additionally, nylon swells upon moisture uptake of amide chains (-CO-NH-) of $\mathrm{N}$ fibers ${ }^{51}$ and its bonding to polymer backbone improving stiffness and allowing greater capacity for tensile stresses ${ }^{52}$ which may also improve the impact resistance. Relatively cheaper $\mathrm{N}$ fibers can therefore be replaced with $\mathrm{P}$ fibers safely by half of volume in favor of enhancing flexural impact resistance without sacrificing the basic mechanical properties of HPFRC mixtures.

Another factor that can be influential on the impact performance of HPFRC mixtures is the orientation and uniform distribution of individual fibers which are affected by the mixtures' processing/casting procedure and specimen/structural dimensions. ${ }^{53}$ For example, by changing the distribution of fibers from 1D uniform alignment to 3D random distribution, load carrying capacity of a composite can be reduced by $20 \%{ }^{54}$ Likewise, flexural impact load carrying capacity of HPFRC mixtures can be modified by changing the orientations of individual fibers especially within the impact zone. It is expected that the fibers incorporated in HPFRC mixtures produced herein are 2D-oriented due to limited cross section $\left(50 \times 50 \mathrm{~mm}^{2}\right)$ of beams. $2 \mathrm{D}$-oriented distribution of fibers results in higher tensile stress and bridging capacity than 3D-oriented distribution (e.g., in the case of specimens with larger dimensions such as beams and columns). Increased bridging capacity improves the ductility by increasing the range of flaw sizes. ${ }^{55}$ Increments in fiber volume and replacement of $\mathrm{P}$ fibers with $\mathrm{N}$ fibers may have played a role in changing the overall orientation of fibers within the limited cross section of beam specimens where impact load was applied and as a result improved the impact performance. However, it needs to be stated that this explanation requires further clarification by testing of specimens with different sizes and techniques (e.g., fluorescence microscopy and digital image analysis $)^{56}$ which is beyond the scope of current paper.

\subsection{2 | Effect of aggregate content}

The second variable of the experimental program was $\mathrm{A} / \mathrm{B}$ ratio. A rigorous comparison regarding the $\mathrm{A} / \mathrm{B}$ ratio and its 

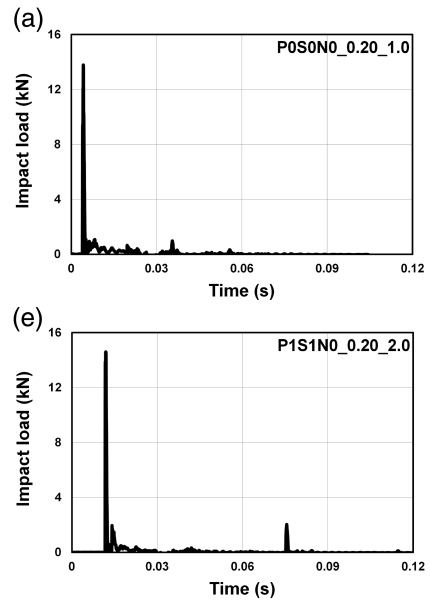

(b)
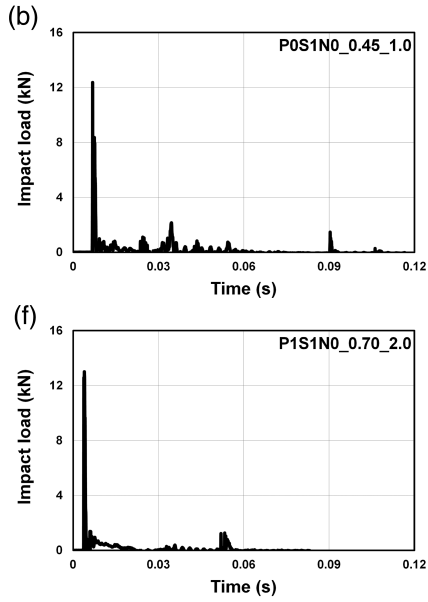
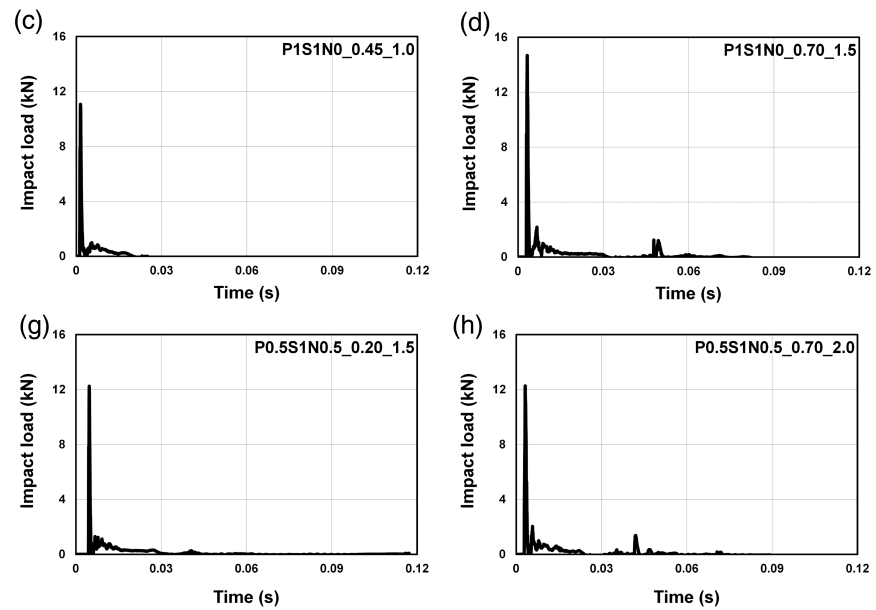

FIGURE 6 Representative impact load versus time graphs for selected specimens from different mixtures

effects on the impact performance of HPFRC mixtures can only be made considering mixtures with the same fiber type/amount and FA/PC. Therefore, mixtures numbered from 7 to 15 and 16 to 24 were compared among themselves. For example, average of left and right displacements for P1S1N0_0.20_1.0, P1S1N0_0.20_1.5, and P1S1N0_0.20_2.0 mixtures were noted to be $-26.8 \mathrm{~mm},-30.3 \mathrm{~mm}$, and -31.5 $\mathrm{mm}$, respectively. Same results for P1S1N0_0.20_1.0, P1S1N0_0.20_1.5, and P1S1N0_0.20_2.0 mixtures were $18.2 \mathrm{~mm},-21.8 \mathrm{~mm}$, and $-24.6 \mathrm{~mm}$, respectively following a similar incremental trend (Table 2). These results therefore suggest that increased amounts of coarse aggregates in the case of hybrid-fiber reinforced HPFRC mixtures led impact resistance to decrease although rates of decrement were not that dramatic.

In accordance with the literature, concrete mixtures outperform paste mixtures in terms of impact resistance given their higher energy need to cause final fracture. ${ }^{28}$ Likewise, it was anticipated that increasing the amount of coarse aggregates would also result in increased impact performance of HPFRC mixtures thanks to increased toughness, modulus of elasticity, and cracking tortuosity. However, it seems that different from incorporating coarse aggregates into pastes, increasing the amount of coarse aggregates in the presence of hybrid fibers clearly differs from the perspective of impact resistance. Authors have previously shown that the HPFRC mixtures produced in this study were with similar elastic modules and toughnesses (according to their flexural stressdeflection graphs) irrespective of the selected $\mathrm{A} / \mathrm{B}$ ratios. ${ }^{7}$ Therefore, these parameters (elastic modulus and toughness) which are likely to change with the changes in the amount of coarse aggregates and be influential on the impact performance of HPFRCs were not considered to have paramount effect on the overall observed behavior. Rather than these parameters, it is believed that effects of coarse aggregates on the flexural ductility and rapid extension of cracks available in the interfacial transition zones (ITZs) between the coarse aggregates and cementitious paste are more pronounced on the impact performance of HPFRC mixtures with hybrid fibers. As can be seen from Table 1, generally, there were reductions in the flexural displacement results with the increased $\mathrm{A} / \mathrm{B}$ ratios for a given fiber type and $\mathrm{FA} / \mathrm{PC}$ although deflection-hardening response was still guaranteed for all HPFRC mixtures. ${ }^{7}$ This might be one of the reasons for reduced impact resistance of mixtures with higher amounts of coarse aggregates. Under impact loading, (different from slow-motion compressive and flexural loading discussed in Section 3.1) specimens are stressed very rapidly which forces large number of microcracks available especially within the ITZs and cementitious paste to extent very rapidly. Hence, it is very likely for these cracks to be forced to propagate through the coarse aggregates rather than traveling around them. ${ }^{57-59}$ This may eliminate the role of coarse aggregates to act like barriers to rapid crack propagation and reduce the impact resistance of HPFRC mixtures as well.

\subsection{3 | Effect of FA content}

As the amount of FA increased, acceleration results increased while displacement results decreased. This finding was observed in all proposed HPFRC mixtures, with and without different fiber combinations. In the reference HPFRC beam specimens, when FA/PC ratio was increased from 0.20 to 0.45 , the average acceleration obtained from the left and right sides of the specimens increased by $11 \%$, while the average displacement reduced by $10 \%$. When FA/PC ratio was increased from 0.45 to 0.70 for the same specimens, the average of acceleration results increased by $12 \%$ and displacement results decreased by $8 \%$. In HPFRC beam specimens reinforced with only $\mathrm{S}$ fibers, when the $\mathrm{FA} / \mathrm{PC}$ ratio was increased from 0.20 to 0.45 , average acceleration and displacement results increased by $8 \%$ and decreased by $9 \%$, respectively. When FA/PC ratio was increased from 0.45 to 0.70 , average acceleration and displacement results for the same specimens increased by $10 \%$ and decreased by $7 \%$, respectively. When the ratio was increased from 0.20 to 0.45 for specimens with $\mathrm{S}$ and $\mathrm{P}$ fibers, average acceleration results 
TABLE 2 Free fall drop-weight test results

\begin{tabular}{|c|c|c|c|c|c|c|c|c|c|}
\hline \multirow[b]{3}{*}{ Mix. No } & \multirow[b]{3}{*}{ Mix. ID } & \multicolumn{4}{|c|}{ Acceleration-g $\left(\mathbf{m} / \mathbf{s}^{2}\right)$} & \multirow{2}{*}{\multicolumn{2}{|c|}{ Displacement (mm) }} & \multirow[b]{3}{*}{ Impact load (kN) } & \multirow[b]{3}{*}{ Residual displacement (mm) } \\
\hline & & \multicolumn{2}{|c|}{ Left } & \multicolumn{2}{|l|}{ Right } & & & & \\
\hline & & Max. & Min. & Max. & Min. & Left & Right & & \\
\hline 2 & POSON0_0.45_1.0 & 132.0 & -118.2 & 140.0 & -139.9 & -40.8 & -39.1 & 12.3 & 30.1 \\
\hline 3 & POSONO_0.70_1.0 & 152.3 & -533.1 & 156.0 & -418.3 & -36.8 & -36.8 & 12.3 & 24.9 \\
\hline 4 & P0S1N0_0.20_1.0 & 188.0 & -303.2 & 187.3 & -331.7 & -34.8 & -33.2 & 12.0 & 27.1 \\
\hline 6 & P0S1N0_0.70_1.0 & 227.2 & -284.0 & 225.3 & -377.5 & -29.6 & -27.9 & 12.3 & 27.8 \\
\hline 7 & P1S1N0_0.20_1.0 & 216.1 & -334.2 & 223.4 & -265.5 & -25.9 & -27.6 & 12.2 & 19.8 \\
\hline 8 & P1S1N0_0.45_1.0 & 258.7 & -557.0 & 267.4 & -442.2 & -21.3 & -25.3 & 11.1 & 11.8 \\
\hline 9 & P1S1N0_0.70_1.0 & 319.5 & -372.0 & 327.1 & -552.8 & -20.3 & -22.8 & 12.4 & 11.8 \\
\hline 10 & P1S1N0_0.20_1.5 & 263.0 & -262.9 & 261.2 & -260.9 & -29.1 & -31.4 & 14.5 & 13.4 \\
\hline 14 & P1S1N0_0.45_2.0 & 356.7 & -445.6 & 334.8 & -531.0 & -28.8 & -30.4 & 12.1 & 15.6 \\
\hline 15 & P1S1N0_0.70_2.0 & 423.4 & -423.3 & 431.6 & -540.6 & -26.6 & -27.8 & 12.9 & 20.1 \\
\hline 16 & P0.5S1N0.5_0.20_1.0 & 300.9 & -512.4 & 315.4 & -342.7 & -19.4 & -17.1 & 12.2 & 14.3 \\
\hline 17 & P0.5S1N0.5_0.45_1.0 & 349.5 & -902.3 & 350.0 & -491.4 & -12.8 & -12.1 & 12.5 & 5.49 \\
\hline 18 & P0.5S1N0.5_0.70_1.0 & 471.9 & -557.0 & 473.7 & -552.8 & -10.3 & -10.9 & 12.2 & 4.89 \\
\hline 19 & P0.5S1N0.5_0.20_1.5 & 376.4 & -557.0 & 388.9 & -546.0 & -22.2 & -21.4 & 12.2 & 16.6 \\
\hline 20 & P0.5S1N0.5_0.45_1.5 & 429.1 & -662.8 & 432.4 & -417.4 & -14.8 & -15.6 & 12.2 & 9.26 \\
\hline 21 & P0.5S1N0.5_0.70_1.5 & 572.3 & -983.0 & 571.8 & $-1,233$ & -12.1 & -11.4 & 12.7 & 8.07 \\
\hline 22 & P0.5S1N0.5_0.20_2.0 & 421.7 & -421.6 & 423.3 & -818.1 & -24.4 & -24.8 & 12.3 & 19.2 \\
\hline
\end{tabular}

increased by $16 \%$ and displacement results decreased by $10 \%$. When the ratio was increased from 0.45 to 0.70 , average acceleration increased by $17 \%$ while displacement decreased by $10 \%$. Finally, in the specimens produced with three different fibers, increasing FA/PC ratio from 0.20 to 0.45 caused average acceleration results to increase by $11 \%$ and displacement results to decrease by $32 \%$. By increasing FA/PC ratio for the same specimens from 0.45 to 0.70 , average acceleration results increased by $25 \%$ and displacement results decreased by $18 \%$.

Results clearly show that higher amounts of FA improved the rigidity, acceleration capacity, and impact resistance of HPFRC mixtures under sudden loading. It also reduced displacement with impact loading and enhanced resistance to higher rates of acceleration and impact energy. This outcome was valid even for reference specimens without fibers. To be more precise, increased FA was the most effective in increasing acceleration and decreasing displacement for specimens reinforced with three different fibers. The possible explanation for more pronounced impact performance in HPFRC specimens with hybrid fibers and increased FA may be the influence of FA particles in more uniformly distributing individual fibers due to their spherical surface characteristics and ability to lower matrix fracture toughness results in favor of achieving increased ductility (flexural displacement) (Table 1).

\subsection{4 | Residual displacement}

In addition to maximum displacement values measured at the first moment of drop hammer impact, the residual displacement values remained on the beam specimens after the completion of impact tests were measured for all specimens as well. Residual displacement values remaining on beam specimens after completion of impact loading are listed in the last column of Table 2. Based on the residual displacement results and typical cracking behavior after impact loading (Figure 7), maximum damage occurred in reference specimens, with an average residual displacement of $27.9 \mathrm{~mm}$ for the specimen series with no fibers. Average residual displacement of specimens with only $\mathrm{S}$ fibers was very close to that of reference specimens at $27.4 \mathrm{~mm}$. For those incorporating $\mathrm{S}$ and $\mathrm{P}$ fibers, the value was $15.1 \mathrm{~mm}$, which was $45 \%$ smaller than that obtained from specimens without fibers and with only $\mathrm{S}$ fibers. Average residual displacement in specimens with three different fibers was $10.67 \mathrm{~mm}$, which was $30 \%$ smaller than the values of specimens with $\mathrm{S}$ and $\mathrm{P}$ fibers. Maximum and residual displacement values were comparably lower in specimens reinforced with $\mathrm{P}, \mathrm{S}$, and $\mathrm{N}$ fibers. These findings demonstrate that HPFRC beams with three different fibers were 
(a)

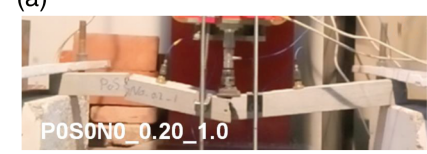

(e)

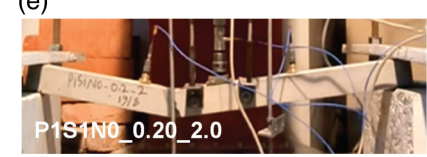

(b)

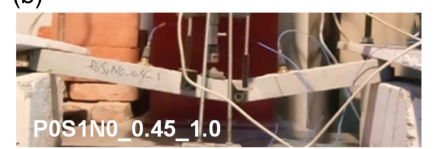

(f)

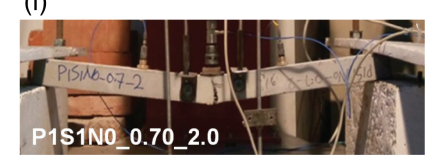

(c)

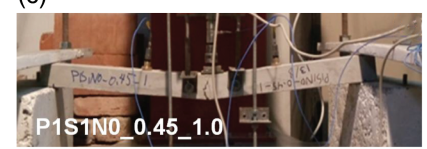

(g)

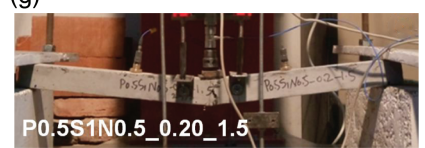

(d)

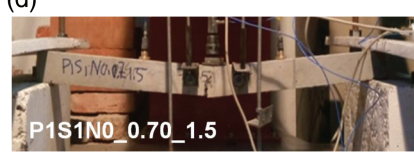

(h)

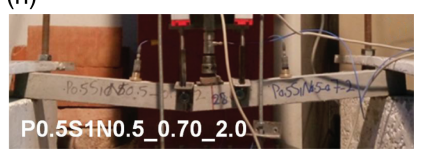

FIGURE 7 Representative views of the specimens from different mixtures after final failure

the least affected by the impact load which were also in line with previously reported results.

\section{3 | Nonlinear finite element simulation of test specimens}

In the numerical part of the study, an explicit module of the ABAQUS finite element analysis software was used to investigate the behavior of structural members underperformed dynamic effects for nonlinear analysis. Test setup and specimens were modeled in the software, and element types, material properties, mesh sizes, time steps, and boundary were defined. Specimen sizes and support conditions were noted, as in the test program. No external forces were applied to the system, excluding gravitational force. As in the experimental program, the drop height and mass of the steel drop hammer were $600 \mathrm{~mm}$ and $9 \mathrm{~kg}$ in the analysis, respectively. The element type selected was C3D10M (10-node modified tetrahedron), which gives the best results under dynamic effects. A steel plate was located on the midpoint of specimen to prevent local crushing from the point of impact loading. Finite element models were created after completing the node and element numbers of the test specimen, hammer, and steel plate. Since specimen sizes were the same, the same node and element numbers were defined in the software. Impact load should be transferred completely to the specimen for the consistency between experimental and numerical studies. For this reason, each model is analyzed for different increment sizes and impact moment of the hammer to the specimen is determined.

Material properties were assigned to the related geometries in the software. The software's concrete damage plasticity model was used to define nonlinear behavior of concrete material. Linear elastic material models were defined for the steel hammer and plate, as presented in Table 3. Properties of HPFRC mixtures changed, since the material properties and fractions of ingredients in the mixtures were relatively different. As a result of tests performed on HPFRC mixtures used in producing beam specimens, compressive stressstrain and uniaxial tensile stress-strain graphs of each mixture were obtained experimentally. In the finite element analysis, material models obtained separately for each beam specimen in both compression and uniaxial tensile stressstrain were used and entered into the ABAQUS software as raw data. Examples selected from material models used in the analysis of test specimens are shown in Figures 8 and 9 for compressive and uniaxial tensile stresses, respectively.

After material properties were assigned to the related geometries, analysis type was determined. Here, C3D10M elements which are compatible with contact problems were used in the analysis. These members can only be utilized in explicit solutions. After deciding the analysis type, time steps and time spans were defined in the software and time increments were assigned for each drop movement of the hammer. As the analysis was an incremental dynamic one, it was performed for short time intervals to reach the proper results. So, time increment was selected as $2 \times 10^{-8} \mathrm{~s}$ when the hammer started to apply loading to the test specimen.

Mesh structure of the model is determined according to the element and analysis types. Based on a comparative and sensitivity analysis of results between 10 and $30 \mathrm{~mm}$ mesh sizes, $15 \mathrm{~mm}$ mesh was chosen. Fixed supports were defined for each end of the specimen. On the other hand, the steel hammer was modeled to enable the vertical movement only and horizontal movement of the hammer is restrained.

Contact between the hammer and specimen was modeled by defining contact surfaces. For this purpose, surface to surface contact was selected between the steel hammer and test specimen. Surface of the hammer applying the impact load was chosen as master, and the corresponding part of the specimen was chosen as slave. Tangential and normal behavior contact properties were selected in the software to model contact between the hammer and specimen. Since friction effects occurred during the experimental program, the coefficient of friction for contact surfaces was taken as 0.02 in tangential behavior. On the other hand, rebound movement of the hammer from the specimen was modeled by normal contact behavior.

A finite elements' analysis was performed for each test specimen. Few test specimens were initially used to calibrate various unmeasured coefficients; for example concrete damage plasticity model coefficients and friction coefficient for contact surface between the hammer and specimen. Acceleration, displacement, impact load, and residual displacements were obtained for various test specimens. Figure 10 shows maximum acceleration versus time, displacement versus time, and impact load versus time graphs from numerical and experimental works for specimens of P1S1N0_0.45_1.0 mixture (Mixture \#8). Graphs were obtained for a single drop of 
the steel hammer so results from the analysis could be compared with the test results. Maximum results obtained from the analysis for all test specimens are summarized in Table 4.

When the results presented in Table 4 are evaluated, it is evident that maximum acceleration ratios obtained from actual experiments and finite element analysis range between 0.80 and 1.10. Maximum displacement ratios obtained from the experiments and finite element analysis range between 0.84 and 1.13. The ratios of residual displacements obtained from the experiments and finite element analysis range between 0.86 and 1.25 . These findings clearly show that results of ABAQUS analysis are in good agreement with the experimental results, confirming the validity of the proposed model.

Von-Misses stress distributions for three test specimens were determined and plotted (Figure 11). High tensile stresses and cracks occurred around the impact load point for all test specimens. Deformed specimen shapes for the same three specimens were also determined and presented in Figure 11. Cracks and distributed damage monitored after the actual experiments were in agreement with figures acquired as a result of the nonlinear finite element analysis. Maximum displacements for the three specimens were observed close to the mid-point where the impact loading was applied, similar to that observed in laboratory experiments.

\section{4 | CONCLUSIONS}

This research evaluated the impact resistance of beam specimens produced with deflection-hardening HPFRC mixtures after free-fall drop-weight tests. Primary importance was given to observing the effects of three main variables (types/amounts of fiber reinforcement, $\mathrm{A} / \mathrm{B}$ ratio, and $\mathrm{FA} / \mathrm{PC}$ ratio) on the impact behavior of HPFRC beams. To do so, acceleration, displacement, and impact load versus time graphs were experimentally obtained and analyzed for HPFRC beam specimens. Furthermore, tested beam

(a)

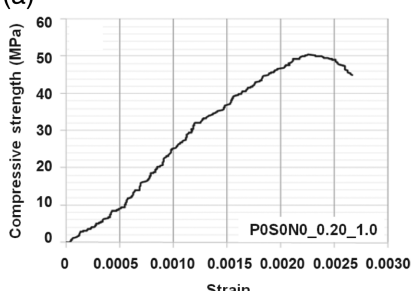

(e)

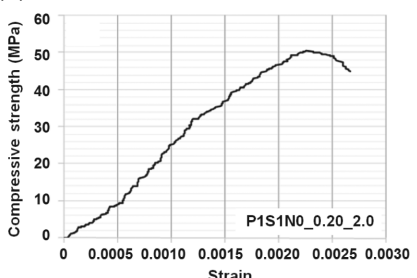

(b)

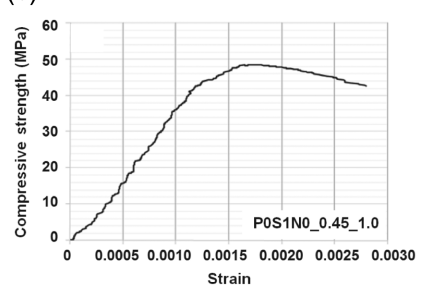

(f)

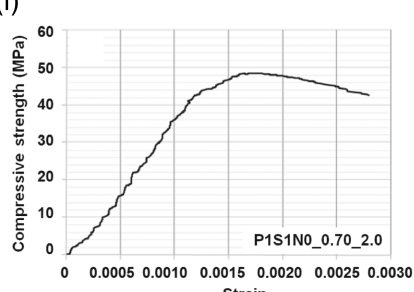

TABLE 3 Material properties of steel hammer and plate used for finite element analysis model

\begin{tabular}{|ll} 
Property & Steel hammer and plate \\
\hline Weight per unit of volume $\left(\mathrm{kg} / \mathrm{m}^{3}\right)$ & 7,850 \\
\hline Modulus of elasticity $(\mathrm{MPa})$ & 200,000 \\
\hline Poisson's ratio & 0.30 \\
\hline Shear modulus $(\mathrm{MPa})$ & 76,923 \\
\hline Bulk modulus $(\mathrm{MPa})$ & 166,670
\end{tabular}

specimens were modeled in a finite element program (ABAQUS) and incremental nonlinear dynamic analyses were performed. Finally, results obtained from the laboratory experiments were compared with those obtained from the numerical study. Following conclusions were drawn:

- Fiber reinforcement was significantly effective in improving the impact resistance of reference HPFRC mixtures without fibers for a given $\mathrm{FA} / \mathrm{PC}$ and $\mathrm{A} / \mathrm{B}$ ratio. Increasing the dosage of fibers improved the impact resistance of HPFRC mixtures so that after the introduction of impact loading, smaller flexural displacements were obtained from beam specimens with two (S, P, by $2 \%$ volume) and three (S, P, N, by $2 \%$ volume) different fibers compared to specimens with only $\mathrm{S}$ (by $1 \%$ volume) fibers. At the same fiber dosage, FA/PC ratio, and A/B ratio, better impact performances were noted from HPFRC beam specimens hybridized with three different fibers $(\mathrm{S}, \mathrm{P}, \mathrm{N})$ than the ones with two different fibers $(\mathrm{S}, \mathrm{P})$ which showed that costly $\mathrm{P}$ fibers can safely be replaced with cheaper $\mathrm{N}$ fibers without risking mechanical properties in favor of achieving enhanced impact resistance.

- Increased A/B ratios resulted in reduced impact resistance of HPFRC beam specimens with hybrid fibers for a given FA/PC ratio and fiber dosage. However, the rates of decrement were not that pronounced even when $\mathrm{A} / \mathrm{B}$ ratio was doubled from 1.0 to 2.0 . It is possible that a different impact behavior (more enhanced) can be

(c)
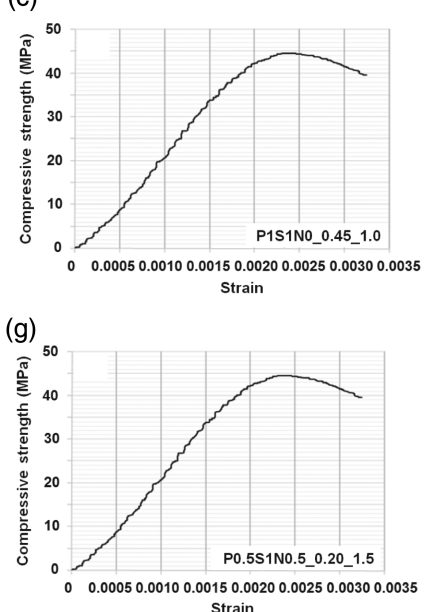

(d)

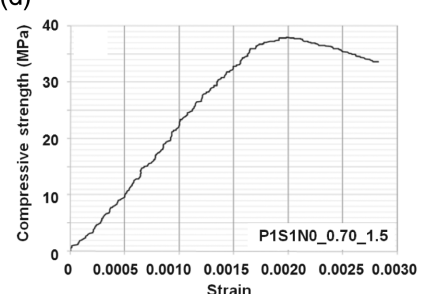
Strain

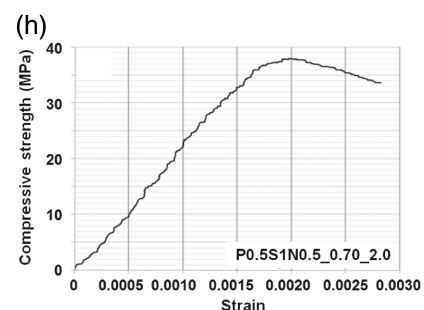

FIGURE 8 Representative compressive stress versus strain models of specimens from different mixtures for FEA model 
(a)

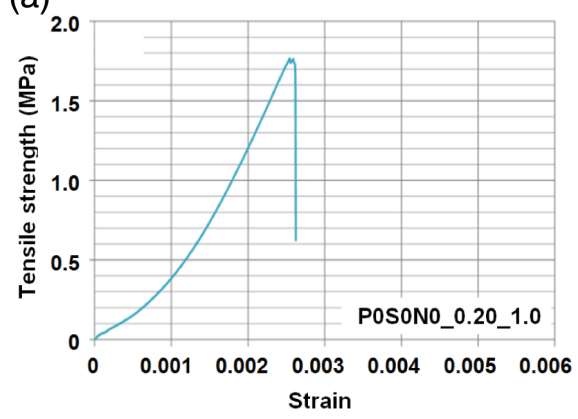

(d)

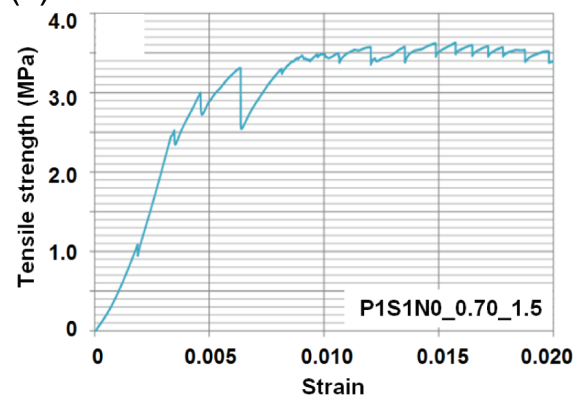

(b)

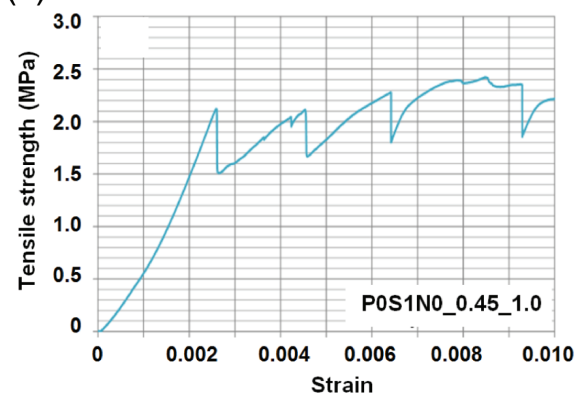

(e)

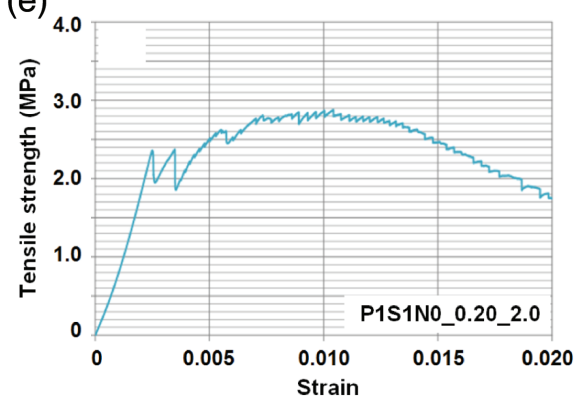

(c)

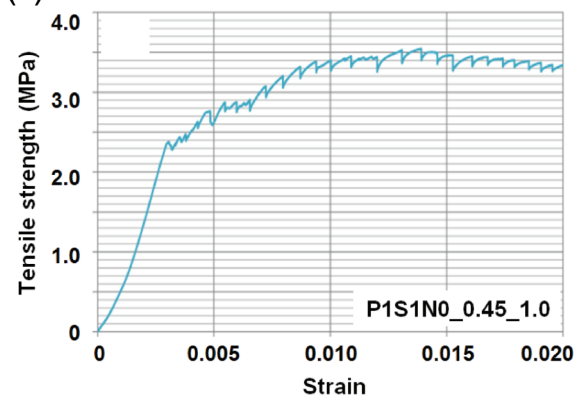

(f)

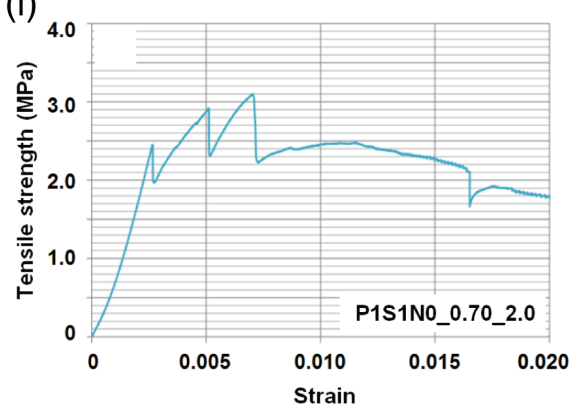

FIGURE 9 Representative uniaxial tensile stress versus strain models of specimens from different mixtures for FEA model

(a)

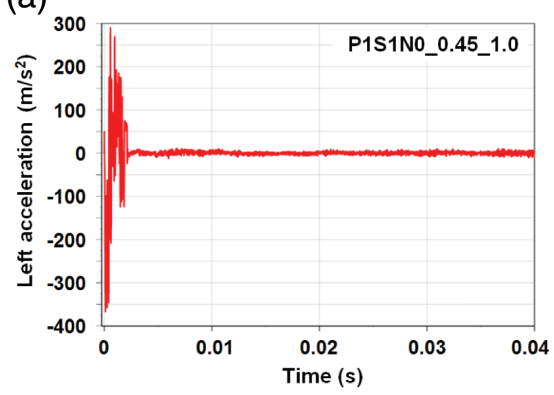

(d)

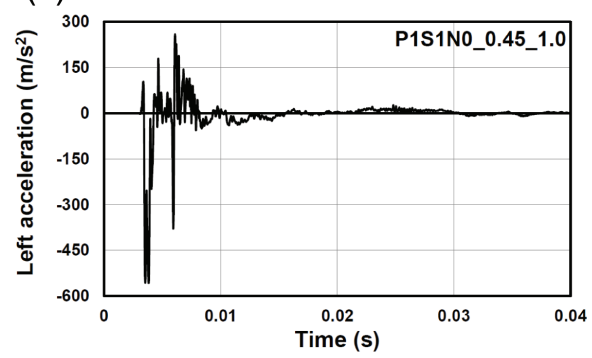

(b)

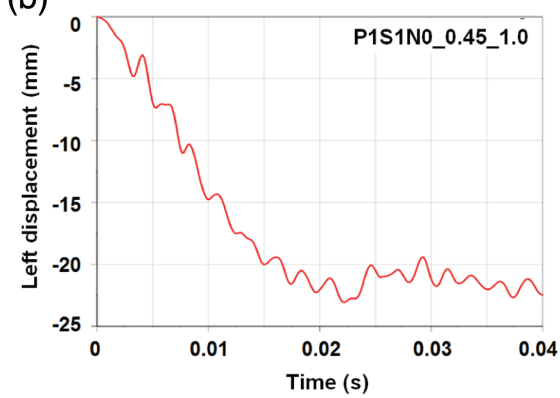

(e)

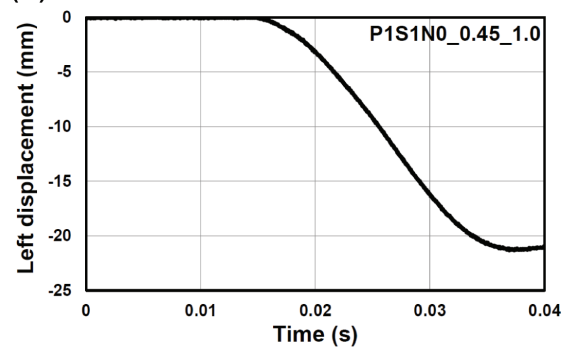

(c)

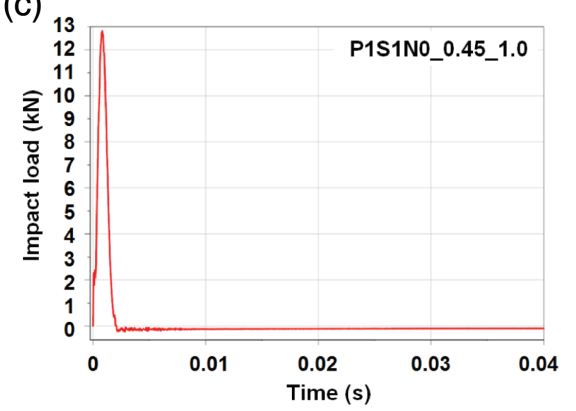

(f)

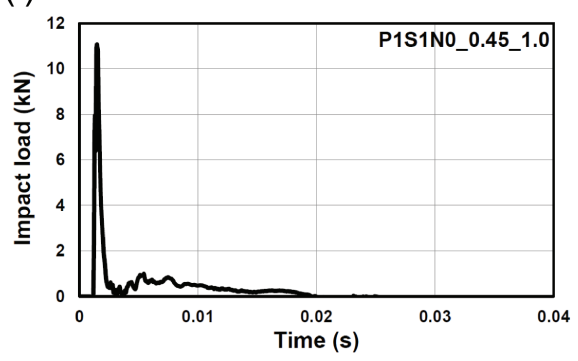

FIGURE 10 Acceleration versus time, displacement versus time, and impact load versus time graphs of specimens of P1S1N0_0.45_1.0 (Mixture \#8) obtained from finite element analysis $(\mathrm{a}, \mathrm{b}, \mathrm{c})$ and from real-time experiments $(\mathrm{d}, \mathrm{e}, \mathrm{f})$

obtained in the presence of relatively high amounts of coarse aggregates when the cross-sectional area of impact, which was relatively small $\left(50 \times 50 \mathrm{~mm}^{2}\right)$ herein, is modified. Increasing the amounts of coarse aggregates without sacrificing the mechanical properties and impact resistance can be very beneficial for minimizing the dimensional stability problems and shrinkagerelated cracking potential of HPFRC mixtures.

- Improved impact performance was obtained when the FA/PC ratios of HPFRC mixtures were increased and this was irrespective of the $\mathrm{A} / \mathrm{B}$ ratio and fiber type/dosage. Increased utilization rates of Class-F FA seem to improve the workability of fresh mixtures, increase the fiber distribution, and reduce matrix fracture toughness in favor of achieving higher flexural displacement and resultingly, enhanced impact performance.

- ABAQUS finite element software, used for the purposes of numerical analysis, was successful in modeling impact behavior of HPFRC beam specimens; acceleration, displacement, and residual displacement results 
TABLE 4 Comparison of experimental and numerical results

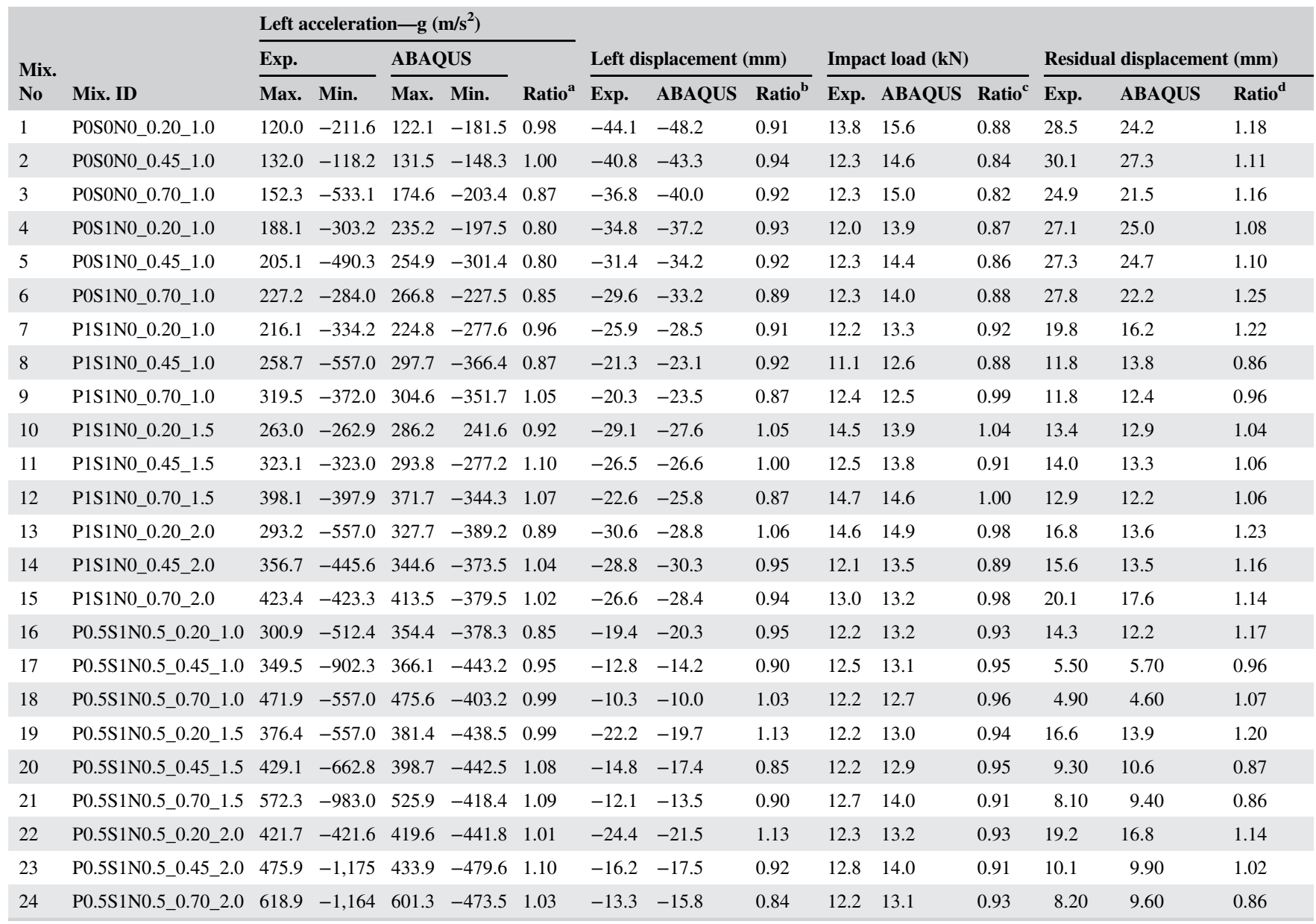

${ }^{a}$ Ratio of left experimental maximum acceleration to numerical maximum accelaration values.

${ }^{\mathrm{b}}$ Ratio of left experimental displacement to numerical maximum displacement values.

${ }^{c}$ Ratio of experimental impact load to numerical impact load values.

${ }^{\mathrm{d}}$ Ratio of experimental residual displacement to numerical residual displacement values.

(a)

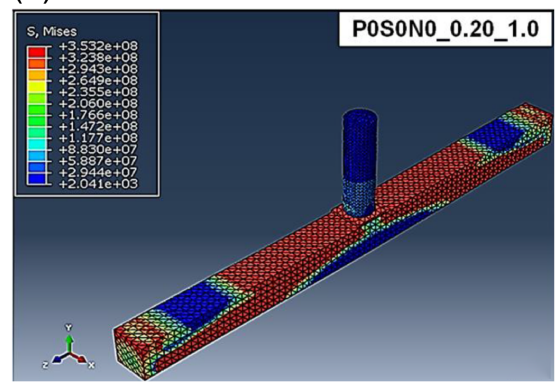

(b)

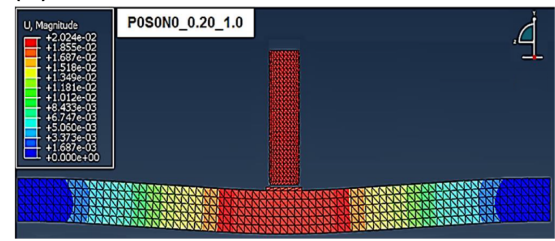

(c)

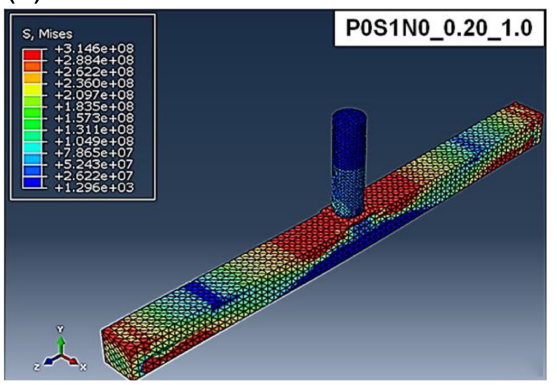

(d)

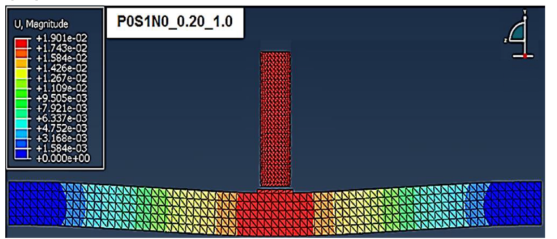

(e)

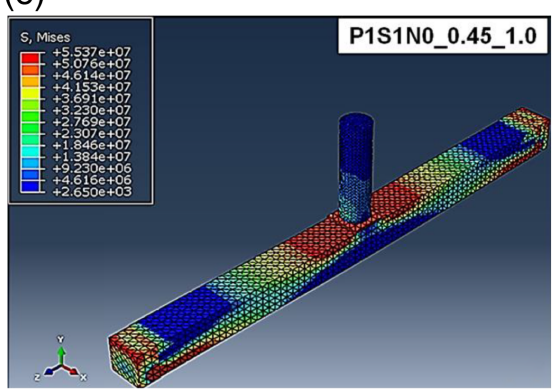

(f)

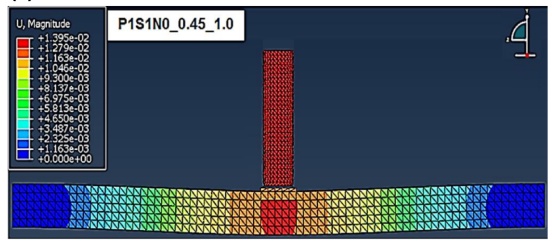

FIGURE 11 Representative stress distributions (a, c, e) and deformed shapes (b, d, f) of specimens from different mixtures during impact

obtained from both experimental and numerical studies were in good agreement. Moreover, beam displacement profiles and stress distributions that were calculated from the numerical analysis were found to be in line with the experimental results. The effects of experimental variables on the displacement results were concordant with 
the numerical analysis, confirming that ABAQUS program can be used in the design process of proposed HPFRC mixtures before implementing actual tests.

Overall, the findings of current study reveal the actual producibility of deflection-hardening HPFRC mixtures with multiple microcracking and improved impact resistance in the presence of large share of coarse aggregates. Although the study will serve as a benchmark for the implementation of further studies in the future and make such materials to be used in actual field conditions at more reasonable prices, more elaborated studies taking into account additional variant parameters in materials' properties/testing procedure (including different specimen dimensions, fiber types/amounts, levels of impact loading etc.) are necessary for a more precise understanding of HPFRCs under impact loading.

\section{ORCID}

Özgür Anıl (1) https://orcid.org/0000-0002-1939-0366

\section{REFERENCES}

1. Şahmaran M, Li VC. Durability properties of micro-cracked ECC containing high volumes fly ash. Cem Concr Res. 2009;39(11):1033-1043.

2. Ma HL, Jia Z, Lau KT, Leng J, Hui D. Impact properties of glass fiber/epoxy composites at cryogenic environment. Compos Part B-Eng. 2016;92:210-217.

3. LaMattina B, Li G, Hui D. Blast/impact on engineered (nano) composite materials. Compos Part B-Eng. 2009;40(6):413-415.

4. Dutta PK, Hui D, Kadiyala SV. A microstructural study of Gr/Ep composite material subjected to impact. Comput Struct. 2000;76(1-3):173-181.

5. Yıldırım G, Şahmaran M, Balçıkanlı M, Özbay E, Lachemi M. Influence of cracking and healing on the gas permeability of cementitious composites. Construct Build Mater. 2015;85:217-226.

6. Alyousif A, Lachemi M, Yıldırım G, Aras GH, Şahmaran M. Influence of cyclic frost deterioration on water sorptivity of micro cracked cementitious composites. J Mater Civil Eng. 2015;28(4):405-419.

7. Banyhussan QS, Yıldırım G, Bayraktar E, Demirhan S, Şahmaran M. Deflection-hardening hybrid fiber reinforced concrete: The effect of aggregate content. Construct Build Mater. 2016;125:41-52.

8. Yıldırım G, Keskin ÖK, Keskin SB, Şahmaran M, Lachemi M. A review of intrinsic self-healing capability of engineered cementitious composites: Recovery of transport and mechanical properties. Construct Build Mater. 2015;101:10-21.

9. Şahmaran M, Yıldırım G, Noori R, Özbay E, Lachemi M. Repeatability and pervasiveness of self-healing in engineered cementitious composites. ACI Mater J. 2015;12(4):513-522.

10. Alyousif A, Lachemi M, Yıldırım G, Şahmaran M. Effect of self-healing on the different transport properties of cementitious composites. J Adv Concrete Technol. 2015;13(3):112-123.

11. Clifton JR. Penetration resistance of concrete-A review. Washington DC: Natl Bureau Stand Spec Publ, 1984;p. 480-445.

12. Badr A, Ashour AF, Platten AK. Statistical variations in impact resistance of polypropylene fiber-reinforced concrete. Int J Impact Eng. 2006;32(11):1907-1920.

13. Marar K, Çelik T, Eren Ö. Relationship between impact energy and compression toughness energy of high-strength fiber reinforced concrete. Mater Lett. 2001;47(4-5):297-304.

14. Nataraja MC, Nagaraj TS, Basavaraja SB. Reproportioning of steel fiber reinforced concrete mixes and their impact resistance. Cem Concr Res. 2005;35(12):2350-2359.

15. Valipour HR, Huynh L, Foster SJ. Analysis of RC beams subjected to shock loading using a modified fibre element formulation. Comput Concr. 2009;6 (5):377-390

16. Anıl Ö, Durucan C, Erdem RT, Yorgancilar MA. Experimental and numerical investigation of reinforced concrete beams with variable material properties under impact loading. Construct Build Mater. 2016;125:94-104.
17. Hannawi K, Bian H, Prince-Agbodjan W, Raghavan B. Effect of different types of fibers on the microstructure and the mechanical behavior of ultra-high performance fiber-reinforced concretes. Compos Part B-Eng. 2016;86:214-220.

18. Kantar E, Erdem RT, Anıl Ö. Nonlinear finite element analysis of impact behavior of concrete beam. Math Comput Appl. 2011;16(1):183-193.

19. Kantar E, Anıl Ö. Low velocity impact behavior of concrete beam strengthened with CFRP strip. Steel Compos Struct. 2012;12(3):207-230.

20. Yang HX, Li J, Huang YS. Study on the mechanical properties of high performance hybrid fiber reinforced cementitious composite (HFRCC) under impact loading. Key Eng Mater. 2015;629:79-84.

21. Yılmaz MC, Anıl Ö, Alyavuz B, Kantar E. Load displacement behavior of concrete beam under monotonic static and low velocity impact load. Int J Civil Eng. 2014;12(4):488-503.

22. Anıl Ö, Yılmaz T. Low velocity impact behavior of shear deficient RC beam strengthened with CFRP strips. Steel Compos Struct. 2015;19(2):417-439.

23. Kishi N, Konno H, Ikeda K, Matsuoka KG. Prototype impact tests on ultimate impact resistance of PC rock-sheds. Int J Impact Eng. 2002;27(9):969-985.

24. Ong KCG, Basheerkhan M, Paramasivam P. Resistance of fibre concrete slabs to low velocity projectile impact. Cem Concr Compos. 1999;21(5-6):391-401.

25. Mindess S, Yan C. Perforation of plain and fibre reinforced concretes subjected to low-velocity impact loading. Cem Concr Res. 1993;23(1):83-92.

26. Barr B, Baghli A. A repeated drop-weight impact testing apparatus for concrete. Mag Concr Res. 1988;40(144):167-176.

27. Siewert TA, Manahan MP, McCowan CN, Holt JM, Marsh FJ, Ruth EA. The history and importance of impact testing. In pendulum impact testing: A century of progress. ASTM Int. 2000;1380:3-16.

28. Banthia NP Impact resistance of concrete [doctoral dissertation]. University of British Columbia, 1987.

29. Bull PH, Edgren F. Compressive strength after impact of CFRP-foam core sandwich panels in marine applications. Compos Part B-Eng. 2004;35(6-8):535-541.

30. Maalej M, Zhang J, Quek ST, Lee SC. High-velocity impact resistance of hybrid-fiber engineered cementitious composites. 5th International Conference on Fracture Mechanics of Concrete and Concrete Structures-FraMCoS5. 2004. 1051-1058.

31. De Koker D, van Zijl GPAG. Extrusion of engineered cement-based composite material. 6th RILEM Symposium on Fiber-Reinforced Concretes (FRC). 2004. 20-22.

32. Soroushian P, Nagi M, Hsu J. Optimization of the use of lightweight aggregates in carbon fiber reinforced cement. ACI Mater J. 1992;89:267-276.

33. Li VC, Mishra DK, Wu HC. Matrix design for pseudo-strain-hardening fibre reinforced cementitious composites. Mater Struct. 1995;28(10):586-595.

34. Şahmaran M, Yücel HE, Demirhan S, Li VC. Combined effect of aggregate and mineral admixtures on tensile ductility of engineered cementitious composites. ACI Mater J. 2012;109(6):627-638.

35. Ahmed SFU, Maalej M. Tensile strain hardening behaviour of hybrid steelpolyethylene fibre reinforced cementitious composites. Construct Build Mater. 2009;23(1):96-106.

36. Blunt JD, Ostertag CP. Deflection hardening and workability of hybrid fiber composites. ACI Mater J. 2009;106(3):265-272.

37. Hay R, Ostertag C. Development and application of high performance green hybrid fiber reinforced concrete (HP-G-HyFRC) for sustainable and energyefficient buildings. Key Eng Mater. 2014;629:299-305.

38. Maalej M, Quek ST, Zhang J. Behavior of hybrid-fiber engineered cementitious composites subjected to dynamic tensile loading and projectile impact. J Mater Civil Eng. 2005;17(2):143-152.

39. Chen Z, Yang Y, Yao Y. Impact properties of engineered cementitious composites with high volume fly ash using SHPB test. J Wuhan Univ Technol. 2012;27(3):590-596.

40. Yang $\mathrm{EH}, \mathrm{Li}$ VC. Tailoring engineered cementitious composites for impact resistance. Cem Concr Res. 2012;42(8):1066-1071.

41. Mechtcherine V, Millon O, Butler M, Thoma K. Mechanical behaviour of strain hardening cement-based composites under impact loading. Cem Concr Compos. 2011;33(1):1-11.

42. Kang ST, Choi JI, Koh KT, Lee KS, Lee BY. Hybrid effects of steel fiber and microfiber on the tensile behavior of ultra-high performance concrete. Compos Struct. 2016;145:37-42.

43. Yoo DY, Yoon YS, Banthia N. Flexural response of steel-fiber-reinforced concrete beams: Effects of strength, fiber content, and strain-rate. Cem Concr Compos. 2015;64:84-92.

44. Wang S, Li VC. Engineered cementitious composites with high-volume fly ash. ACI Mater J. 2007;104(3):233-241. 
45. Qian CX, Stroeven P. Development of hybrid polypropylene-steel fibrereinforced concrete. Cem Concr Res. 2000;30(1):63-69.

46. Shaikh FUA. Deflection hardening behaviour of short fibre reinforced fly ash based geopolymer composites. Mater Design. 2013;50:674-682.

47. Ranade R, Li VC, Heard WF, Williams BA. Impact resistance of high strength-high ductility concrete. Cem Concr Res. 2017;98:24-35.

48. Mao L, Barnett SJ, Tyas A, Warren J, Schleyer GK, Zaini SS. Response of small scale ultra high performance fibre reinforced concrete slabs to blast loading. Construct Build Mater. 2015;93:822-830.

49. Barnett S, Millard S, Tyas A, Schleyer G. Briefing: Blast tests of fibrereinforced concrete panels. Constr Mater. 2010;163(3):127-129.

50. van Mier JGM. Fracture process of concrete: Assessment of material parameters for fracture models. Boca Rotan, FL: CRC Press, 1997.

51. Harold FGJ, John RWJ, Eldridge MMIII. Extrusion: The definitive processing guide and handbook. New York, NY: William Andrew, 2005.

52. Yap SP, Alengaram UJ, Jumaat MZ. Enhancement of mechanical properties in polypropylene-and nylon-fibre reinforced oil palm shell concrete. Mater Design. 2013;49:1034-1041.

53. Ranade R. Advanced cementitious composite development for resilient and sustainable infrastructure [PhD dissertation]. Ann Arbor (MI): University of Michigan, 2014.

54. Cox HL. The elasticity and strength of paper and other fibrous materials. $\mathrm{Br}$ J Appl Phys. 1952;122(1):10-18.

55. Ranade R, Stults MD, Lee B, Li VC. Effects of fiber dispersion and flaw size distribution on the composite properties of PVA-ECC. In: Parra-Montesinos GJ, Reinhardt HW, Naaman AE, editors. High performance fiber reinforced cement composites 6. Dordrecht: Springer, 2012; p. 107-114.

56. Lee BY, Kim JK, Kim JS, Kim YY. Quantitative evaluation technique of polyvinyl alcohol (PVA) fiber dispersion in engineered cementitious composites. Cem Concr Compos. 2009;31(6):408-417.

57. Zielinski AJ. Fracture of concrete under impact loading. International conference on structural impact and crashworthiness. 1984;654-665.

58. Bentur A, Mindess S. The effect of concrete strength on crack patterns. Cem Concr Res. 1986;16(1):59-66.

59. Zhang MH, Shim VPW, Lu G, Chew CW. Resistance of high-strength concrete to projectile impact. Int J Impact Eng. 2005;31(7):825-841.

\section{AUTHOR BIOGRAPHIES}

Qais S. Banyhussan
Department of Highway and Trans-
portation Engineering
Al-Mustansiriya University
Baghdad, Iraq
qaisalmusawi@yahoo.com

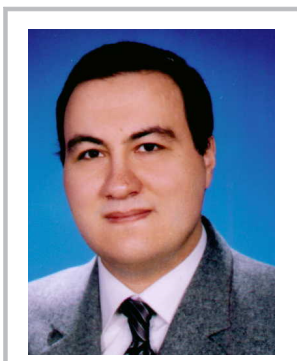

Özgür Anıl

Department of Civil Engineering Gazi University

Ankara, Turkey

oanil@gazi.edu.tr

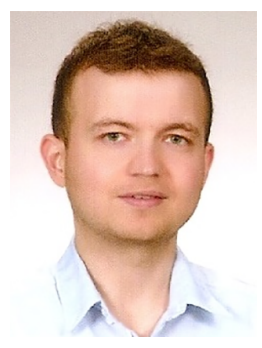

Recep T. Erdem

Department of Civil Engineering

Manisa Celal Bayar University

Manisa, Turkey

tugrul.erdem@bayar.edu.tr

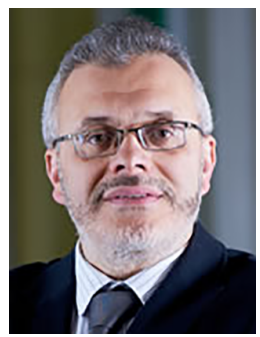

Ashraf Ashour

Department of Civil Engineering

University of Bradford

Bradford, UK

a.f.ashour@bradford.ac.uk

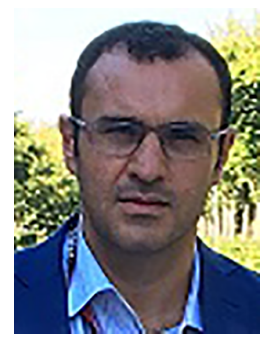

Mustafa Şahmaran

Department of Civil Engineering

Hacettepe University

Ankara, Turkey

sahmaran@hacettepe.edu.tr
How to cite this article: Banyhussan QS, Yıldırım G, Anıl Ö, Erdem RT, Ashour A, Şahmaran M. Impact resistance of deflectionhardening fiber reinforced concretes with different mixture parameters. Structural Concrete. 2019;20: 1036-1050. https://doi.org/10.1002/suco.201800233 